\title{
Cardiovascular magnetic resonance assessment of left atrial volumes and function in patients with persistent atrial fibrillation before and after ablation therapy
}

\author{
Lay Koon Tan ${ }^{1,3^{*}}$, Shouvik Haldar ${ }^{1,2}$, Rick Wage ${ }^{1}$, Jennifer Keegan ${ }^{1,2}$, Tom Wong ${ }^{1,2}$, Raad H Mohiaddin ${ }^{1,2}$ \\ From 16th Annual SCMR Scientific Sessions \\ San Francisco, CA, USA. 31 January - 3 February 2013
}

\section{Background}

Atrial fibrillation (AF) disrupts coordinated atrial electrical and mechanical function which may lead to adverse atrial remodelling if persistent. This study aims to assess both left atrial (LA) volume and function by cardiovascular magnetic resonance (CMR) in patients with persistent AF both before and after restoration to sinus rhythm by ablation therapy.

\section{Methods}

A Siemens scanner (Avanto, 1.5T) was used to study 13 patients (mean age $65 \pm 9$, 4 females and 9 males) with persistent AF before and 3 months after ablation therapy. Images of the LA were acquired in the two-chamber and four-chamber orientation using a breath-hold ECG-gated steady state free precession cine sequence. Biplane arealength method was used to measure the LA end-systolic (ESV) and end-diastolic (EDV) volumes[1]. LA function was determined by its calculated ejection fraction $(E F=(E D V-E S V) / E D V)$ [1]. Seven-day rhythm tape was used to assess patients' rhythm 3 months after ablation. All 13 patients underwent either surgical or catheter ablation therapy successfully, achieving sinus rhythm post procedure. Only 2 patients reverted to AF at 3 months.

\section{Results}

There is a significant reduction in both indexed (volumes by body surface area) LA ESV and EDV 3 months after ablation therapy (iESV baseline $51 \pm 13.8 \mathrm{ml}, 3$ months $36.3 \pm 13.1 \mathrm{ml}, \mathrm{p}=0.01$; iEDV baseline $59.2 \pm 14.8 \mathrm{ml}$,

${ }^{1}$ CMR, Royal Brompton Hospital, London, UK

Full list of author information is available at the end of the article
3 months $48.6 \pm 13.4 \mathrm{ml}, \mathrm{p}=0.03)$. LA EF showed a marked improvement from a baseline of $14.8 \pm 6.1 \%$ to $26.8 \pm 10.8 \%$ at 3 months, $\mathrm{p}=0.006$. Of the 2 patients in sinus rhythm post ablation but reverted to AF at 3 months, the trend is similar (iESV $67.2 \pm 0.4 \mathrm{ml}$ baseline, $52 \pm 15.9 \mathrm{ml}$ at 3 months; iEDV $74.6 \pm 6.2 \mathrm{ml}$ baseline, $64.7 \pm 5.4 \mathrm{ml}$ at 3 months; Baseline EF 9.6 $\pm 7 \%$, 3 months $20.4 \pm 17.9 \%$ ).

\section{Conclusions}

We have demonstrated a marked reduction in CMR measured LA volumes and improvement in LA EF in patients with persistent $\mathrm{AF}$ three months after restoration to sinus rhythm by ablation therapy. This favourable change appears to be sustained even in patients with only transient sinus rhythm.

\section{Funding}

No Funding.

\section{Author details}

${ }^{1}$ CMR, Royal Brompton Hospital, London, UK. ${ }^{2}$ National Heart \& Lung Institute, Imperial College, London, UK. ${ }^{3}$ Cardiology, National Heart Institute, Kuala Lumpur, Malaysia.

Published: 30 January 2013

Reference

1. Sievers B, Kirchberg S, Addo M, Bakan A, Brandts B, Trappe HJ: Assessment of left atrial volumes in sinus rhythm and atrial fibrillation using the biplane area-length method and cardiovascular magnetic resonance imaging with TrueFISP. J Cardiovasc Magn Reson 2004, 6:855-863.

\section{doi:10.1186/1532-429X-15-S1-E98}

Cite this article as: Tan et al:: Cardiovascular magnetic resonance assessment of left atrial volumes and function in patients with persistent atrial fibrillation before and after ablation therapy. Journal of Cardiovascular Magnetic Resonance 2013 15(Suppl 1):E98.

\section{C)

( 2013 Tan et al; licensee BioMed Central Ltd. This is an Open Access article distributed under the terms of the Creative Commons Attribution License (http://creativecommons.org/licenses/by/2.0), which permits unrestricted use, distribution, and reproduction in any medium, provided the original work is properly cited. 